\title{
A review of entrepreneurial leadership learning: an exploration that draws on human, social and institutional capitals
}

\author{
Steve Kempster, Sue Smith and Stewart Barnes
}

\section{INTRODUCTION}

This chapter explores entrepreneurial leadership learning: what it is, and how it is different to leadership learning within employed contexts. We use communities of practice $(\mathrm{CoP})$ theory as a lens for understanding how owner-managers of small and medium-sized enterprises (SMEs) learn entrepreneurial leadership. Drawing upon an empirical case study of an SME leadership development programme and an autoethnographic account of one of the owner-managers (Barnes et al., 2015), we explore how entrepreneurial leadership learning becomes evident in the entrepreneurial context and how it can be developed within a CoP. Developing this further we use the notions of human, social and institutional capitals to illustrate how such learning becomes manifest: the connect between individual skills, knowledge and attitudes within social relationships supported through an organised structure with guiding informal rules of collective engagement.

The organisation of the chapter is as follows. First, we provide an overview of debates and research evidence to delineate the nature of entrepreneurial leadership learning. Recent discussions in the field of leadership have begun to assert an ontological orientation towards relational dynamics rather than essentialist qualities of individuals; that is an emphasis on relational practices and identities formed within specific contexts of both leaders and followers (DeRue and Ashford, 2010). The chapter next explores formative leadership learning and the differences in the employed and the SME and entrepreneurial contexts. We continue looking at the SME context using the lens of CoP theory to examine how a leadership programme helps owner-managers of SMEs develop their entrepreneurial leadership capabilities. We highlight a particular case through an autoethnographic account of an owner-manager which examines the lived experience of entrepreneurial leadership learning. The account is used to show how Leitch et al.'s (2013) three capitals - human, social and institutional - provide an in-depth rich sense of verisimilitude of the experience of all three dimensions. We conclude the chapter by exploring opportunities for the development of research into entrepreneurial leadership learning.

\section{WHAT IS ENTREPRENEURIAL LEADERSHIP LEARNING?}

The field of entrepreneurial leadership is 'in the very early stages of conceptual and theoretical development' (Bagheri and Pihie, 2011: 449; similarly argued in Cogliser and Brigham, 2004; Jensen and Luthans, 2006; Leitch et al., 2013). Gupta et al. (2004: 242) offer a useful definition: 'entrepreneurial leadership that creates visionary scenarios that are used to mobilise a supporting cast of participants who become committed by the vision to the discovery of exploitation of strategic value'. In a recent article, Renko et al. (2015: 2) summarised a range of definitions; the essence of these is to suggest a relational influence process that focuses on vision and exploiting opportunities. They believe this phenomenon can occur in organisations of all sizes. Bagheri and Pihie (2011) suggest that it is a dynamic occurring most prominently during new venture creation and early stages of the development of the venture. Vecchio (2003) places emphasis on taking advantage of opportunities, similar to Surie and Ashley (2008) who extend opportunity recognition to innovation and adaptation.

These definitions are not significantly different to the debates in the leadership field. Leadership is generally considered to be a situated and relational process of influence oriented toward goals, directions, purposes and vision (for a useful review, see Drath et al., 2008). The notion of vision or future-oriented activity is similarly suggested to be an important element of entrepreneurship (Ruvio et al., 2010; Jensen and Luthans, 2005). As such, Vecchio (2003: 304) argues that entrepreneurship should not be considered a distinct field, and learning from the field of leadership might be most useful in the context of business growth and individual development. The orientation of Vecchio's (2003) review of both phenomena was to an (understandable) ontological assumption of leadership as an individual. A similar orientation is adopted by Gupta et al. (2004: 242-245) who sought to fuse the notion of the entrepreneurial emphasis of individuality - self-interest, innovative combinations of available resources, tolerance of uncertainty and risk-bearing, and a proactive, opportunity orientation - with an essentialist perspective of leadership anchored in models of charismatic, transformational and authentic leadership: an individual who can influence followers towards achieving greater performance through appealing to their implicit motivations, often centred on articulating an appealing vision anchored to an ethical basis to decisions and actions centred on participation and involvement.

However, debates in the leadership field suggest that the idealised qualities highlighted as essential for the 'leader' are mostly rare, romanticised (Meindl, 1995) or sacred (Grint, 2010). Alvesson and Sveningsson (2003) have suggested that as they searched for leadership, it disappeared; people were unable to point to it, yet people were mostly accepting that it has significant influence in their lives. Through a critical interpretation of leadership, Kelly (2014) has suggested a negative ontology placing emphasis on the notion of it as an empty signifier: a rarefied phenomenon that we would be better to accept as fluid and under continual social 
(re)construction. In this way individuals (re)create the desire for leadership and connect it to people in perceived leadership roles with an anticipatory identity attribution.

If leadership is seen as rarefied and a floating signifier (Kelly, 2014) then this speaks to the importance of leadership being socially constructed, rather than having a concrete or essentialist quality. Debates in the field of leadership are beginning to take this view. There has been an increasing assertion of an ontological orientation towards relational dynamics rather than essentialist qualities of individuals (Uhl-Bien, 2006), and an increasing attention to relational practices and identities of leaders and followers within a specific context (DeRue and Ashford, 2010) emerging as leadership as practice (Carroll et al., 2008; Raelin, 2011). The importance for us of this discussion is to position entrepreneurial leadership as a socially constructed relational practice. The focus of the practice is toward vision and exploiting opportunity; not centred singularly on an individual's skills, but rather a learnt dynamic that emerges as a consequence of interaction of individuals within leadership relationships situated in a particular contexts, such as the SME. The plurality of people undertaking leadership leans towards a distributed, shared and collective notion of leading, vis-à-vis the leader with followers. In the field of entrepreneurship, similar conclusions have been drawn. For example, Gartner et al. (1994: 6) assert: 'the entrepreneur in entrepreneurship is more likely to be plural rather than singular. The locus of entrepreneurial activity often resides not in one person but many'. Similarly, Cooney (2005: 226) states: 'It is arguable that despite the romantic notion of the entrepreneur as lone hero, the reality is that successful entrepreneurs either built teams about them or were part of a team throughout'.

In a review of literature exploring distributed leadership in SMEs, Cope et al. (2011) suggested entrepreneurial teams are more successful than lone entrepreneurs in surviving and growing. They sought to explore how to develop the SME and the entrepreneur, which we discuss below. The connection of the entrepreneur and their development and the development of the business are fundamentally interconnected through relationships. Leitch et al. (2013) helpfully 'join the dots' together, providing a useful summary of entrepreneurial leadership. They describe it as 'a social process enacted through everyday active encounters as a practice of relational learning'. That is, focused on identifying and exploiting opportunities guided through the 'presence of an entrepreneurial vision' that align to the need for 'processes that nurture innovation through generating and securing resources. All of these aspects enable capacity to undertake continuous exploration and idea generation' (ibid.: 348). The focus of Leitch et al.'s (2013) argument is towards Cope's (2005) notion of a learning dynamic of entrepreneurial leadership; that is, a move from a sole focus on human capital (the entrepreneur) to one including social capital, in essence seeing entrepreneurial leadership as an outcome: the consequence of social interaction. Again, the crossover to debates in leadership is striking. Recently, Drath et al. (2008) have suggested the same: a reorientation of the ontology of leadership to be seen as an outcome. They suggested higher-order outcomes of direction, alignment and commitment. In terms of entrepreneurial leadership these outcomes would be seen to provide an integrative frame to Leitch et al.'s (2013) definition above. Drath et al. (2008) and Leitch et al. (2013) broadly reach similar conclusions with regard to the nature of entrepreneurship, leadership and entrepreneurial leadership. It is best seen as an emergent property of a relational learning dynamic (see also Cope and Watts, 2000; Thorpe et al., 2009; Kempster and Cope, 2010; Cope et al., 2011; and Bagheri and Pihie, 2011). This is important due to the emphasis in terms of social learning that shapes how we learn the practice of leading within a specific context. We shall return to social learning shortly. First, we outline the foundations of leadership learning that inform entrepreneurial leadership and highlight structural limitations of the SME context that limit its manifestation.

\section{FORMATIVE LEADERSHIP LEARNING: THE EMPLOYED AND ENTREPRENEURIAL CONTEXT}

Understandings of entrepreneurial leadership, and to an extent entrepreneurial learning, are embryonic but growing. In contrast, the field of leadership learning is well established. It is broadly accepted that leadership learning occurs through the milieu of lived experience (Davies and Easterby-Smith, 1984; Cox and Cooper, 1989; Jackson and Parry, 2001; Bennis and Thomas, 2002; Hill, 2003; Janson, 2008; Kempster, 2006; McCall, 2004). Earliest reports of such learning have been traced back to the age of four: the experience of the playground and being collected by the teacher to start class; 'leadership is the person in front' (Kempster, 2009). As we travel through our life course the experiences shape our understanding of leadership, and such experiences become manifest in our practice of leading (Kempster, 2006). The experiences and the context in which such experiences occur become all-important to leadership learning.

Drawing on both extant literature and empirical work, Kempster (2009) outlines a model of relational leadership learning that is centred on both intra- and interpersonal dynamics. 'Intra' in the sense of identity, selfefficacy and leadership salience; and 'inter' related to three learning processes: observed, enacted and situated. Kempster suggests the intra- and interpersonal combine to create an emergent and ongoing process of becoming that is centred on relational and participative social learning. Drawing on Bennis and Thomas's (2002) notion of crucibles of learning, the dynamics within contexts are all-important. The contexts of the familial environment, education, first and subsequent employment opportunities, provide a variety of roles and a variety of people to engage with (McCall et al., 1988; McCall, 2004). Within the employed context, leadership is highly valued and 
as a phenomenon is most salient. The consequence is a deepening relationship with leadership; the aspiring leader's closer identification and continual testing (in terms of self-efficacy). The empirical data in Kempster and Cope (2010) also resonate with Avolio's (2005) suggestion of trigger events (similar to Cope and Watts, 2000, on critical incidents in the business venture) acting as catalysts to stimulate learning reorientation.

Kempster (2009) explored how managers have learnt to lead, comparing employed managers with owner-managers, highlighting similarities and differences. The similarities were associated with the formative influences such as familial context, education, first and subsequent employment contexts. The differences related to how owner-managers related to the phenomenon of leadership compared to their employed counterparts. For employed managers, leadership was a highly valued identity. It was a prominent career aspiration. Success in career related to being seen and acknowledged as a 'leader'. The career pathway was an important mechanism that carried these managers through leadership learning experiences. With regard to the owner-managers, however, the relationship with leadership was much more problematic. For many the leadership career pathway was restricted by factors such as a poor boss, a constraining environment, a lack of freedom and a hunger to do their own thing.

Kempster and Cope (2010) show how the entrepreneurial context has a marked impact on entrepreneurial leadership learning. In many ways the entrepreneurial context stifles leadership learning. This does not mean that the entrepreneur is not leading - far from it. Their leadership has a very powerful impact on their employees and the business. Rather, the context limits the stimuli of leadership learning. The outcome is often a form of leadership that draws heavily on early formative experiences, most notably the familial, educational and first employment context. In essence, 'the small business is the dominant situated crucible in which entrepreneurs learn to lead ... [the] relationship between the entrepreneur and his/her business reflects a reinforcing and arguably limiting situation with regard to [entrepreneurial] leadership learning' (Kempster and Cope, 2010: 21-22).

The leadership learning lifeblood of varieties of context, roles and participative relationships is severely limited within the developing business. We outline how this can be addressed later on, in terms of entrepreneurial leadership learning. First, we explore the process of social learning, through the lens of CoP theory, to highlight dynamics of entrepreneurial leadership learning in the SME context.

\section{SOCIAL LEARNING THEORY AND ITS APPLICATION TO ENTREPRENEURIAL LEADERSHIP LEARNING}

We have argued that entrepreneurial leadership learning needs an ontological orientation towards a relational dynamic whereby relational practices, context and identity are paramount. Social learning theories can provide a useful lens for understanding identity and the relational dynamic of entrepreneurial leadership learning. Crucially, these theories adopt a social constructionist perspective which argues that learning (and knowledge) occurs through social participation that takes place in everyday activities, through conversations and interactions between people (Lave and Wenger, 1991; Brown and Duguid, 1991; Gherardi, 1995; Gherardi et al., 1998). This challenges the traditional view of learning as something to be acquired cognitively from a knowledgeable source. Gherardi et al. (1998: 277) argue that if one applies a social perspective to learning, attention shifts from the processing of information and the modifying of cognitive structure to the processes of participation and interaction that provide and sustain the proper context for learning. Learning is seen as a collective activity, a product of and engagement through social activities with people, rather than as an individual phenomenon. For Gherardi et al. (1998), learning is not conceived as a way of coming to know the world, but as a way of becoming part of the social world. Such a view of learning sees knowledge as socially constructed, where learning takes place through engagement.

Recent debates on leadership development share this social view of learning, focusing on it as a socially situated process (Iles and Preece, 2006; Kempster and Stewart, 2010; Raelin, 2011) with activity situated in a collective practice. Entrepreneurial leadership development is also seen as a social process emphasising the relational nature of learning through everyday action (Taylor and Thorpe, 2004; Cope, 2005; Pittaway and Thorpe, 2012). Theorists call for the need to better understand entrepreneurial leadership learning in the context of smaller firms (see Leitch et al., 2013). In response to this call, we argue that CoP theory (as a social learning theory) can act as a useful analytical tool for more fully understanding the entrepreneurial leadership learning process and its relation between identity and context in the small firm. The crux of CoP theory lies in the significance of shifting the analytic focus from the individual as learner, to learning as participation in the social world (Lave and Wenger, 1991; Wenger, 1998). The premise is of learning through participation in social, situated activity, achieved through participation with other people, in a social context. The focus is on the practices of communities, with identity a key feature of the learning process. In this sense, $\mathrm{CoP}$ theory is a heuristic, a way of understanding learning in practice, whereby learning is an integral and inseparable aspect of social practice. The practice of leading within a specific context, that is, the CoP, is an emergent property of a relational learning dynamic whereby the engagement and participation in the community is the basis for learning. 
So, what does this mean in the context of the small firm and entrepreneurial leadership development? It is commonly understood that individuals alone do not create successful firms (Thorpe et al., 2009), and there is a move in entrepreneurial leadership development beyond the skills development of the entrepreneur to the development of their human capital (Leitch et al., 2013). Equally, CoPs do not exist in isolation; their effectiveness is not a matter of their internal development alone, but also a matter of how well they connect with other communities and constituencies inside and outside the organisation (Wenger, 2000). It has been shown that using CoP theory to understand entrepreneurial leadership development involves identity work (Smith, 2011; Smith and Smith, 2013). Smith (2011) argues that the identity of the entrepreneur shifts as leadership becomes increasingly salient to them. Kempster (2009) presents a model of relational leadership learning which highlights the importance of becoming. With a reorientation of the ontology of leadership to be seen as an outcome, the process of becoming through identity work is the consequence of social interaction in leadership contexts.

\section{HOW CAN ENTREPRENEURIAL LEADERSHIP LEARNING BE DEVELOPED?}

Building on the previous argument that entrepreneurial leadership needs to be viewed as an ongoing outcome that is generated from a collective relational process, the development approach needs to be a focus on human and social capitals. Cope et al. (2011) suggest a focus on the entrepreneur (the human capital) and the context in which the entrepreneur is being developed. Leitch et al. (2013: 360) suggest the necessity for entrepreneurial leadership development to connect human capital and social capital with what they describe as 'institutional capital' (Anderson, 2010).

We provide a brief examination of human, social and institutional capitals. When we speak here of human capital we are giving emphasis to the skills, knowledge, attitudes and talents of an individual (Fernandez and Castilla, 2001, cited in Leitch et al., 2013: 350); capital that an individual is able to acquire and develop and use in an exchange process to extract value for their own benefit (Zhu et al., 2005). Social capital is a relational form of capital (Adler and Kwon, 2014). It is formed through resources (actual and potential) that are embedded in a network of relationships, and 'thus comprises both the network and the assets that may be mobilised through the network' (Nahapiet and Ghashal, 1998: 243). The capital exchange process fundamentally works through notions of trust and reciprocity. By investing in the network, individuals can draw on the social capital and 'thereby gain the benefits in the form of superior access to information, power, and solidarity ... and augment their capacity for collective action' (Adler and Kwon, 2014: 21). Social capital is interconnected with human capital. The strength of reciprocation and trust is related with the individual's skills, knowledge and attitudes, such as integrity. If someone has little of value to the network (or in extremis is corrosive to the solidarity of the network), then the ability to draw on the social capital over the medium term is restricted. Institutional capital is less developed than human and social capitals. Leitch et al. helpfully elaborated the concept, drawing on the work of Anderson (2010). It draws from the existence of both human and social capital; without these it would not exist, as it requires something of value for an institution to become developed around (Leitch et al., 2013: 349). Institutional capital exists in institutions (perhaps rather self-evidently). The nature of an institution is centred on notions of organising, rules and governance. Organising around a common purpose, rules that help understand what is allowed, governance structures to enforce/ regulate what is allowed and thereby reduce uncertainty. Institutional capital allows individuals to come together and enable social capital to be generated as it allows enhanced trust and solidarity with reduced risk (ibid.: 361). Drawing on empirical research, Leitch et al. (2013: 360) identified how activities within an executive development programme constituted an institution in terms of being governed by a set of rules and norms that are accepted by all the members. Additionally, they showed the emergence of strong organisational structures - such as agendas and procedures - and the beginnings of governance approaches to handle sharing, collaboration and learning: 'In other words, the emergence of a strong resilient institution that can provide space and support for its members' (ibid.: 360).

The earlier discussion on social learning gives draws emphasis to the process of 'being' active members of CoPs. We describe how institutional capital can be developed through the establishment of a CoP that can enable the development of entrepreneurial leadership through enhancing human, social and institutional capitals. In developing this argument we address two questions:

1. How can a CoP develop entrepreneurial leadership?

2. How does a CoP impact on human, social and institutional capital?

\section{HOW CAN A COMMUNITY OF PRACTICE DEVELOP ENTREPRENEURIAL LEADERSHIP?}

The authors have been involved developing entrepreneurs through a leadership development programme (LEAD) for more than ten years. More than 2000 businesses have participated across the United Kingdom. It has been demonstrated that the programme develops entrepreneurial leadership (see Wren and Jones, 2006, 2012) and that using a CoP approach enables the owner-manager to undertake identity work, shifting their 
identity to that of leader (see Smith, 2011). Over the course of ten months, LEAD engages owner-managers in a process through learning interventions including masterclasses, coaching, action learning, business shadowing, and exchanges and critical reflection. Rather than a taught programme, the focus is on building a CoP whereby the delegates become co-learners, who all have a valid contribution to make to the community. Learning arises from participation in the $\mathrm{CoP}$ and gaining recognised membership within that community (see Lave and Wenger, 1991). The activity for the delegates on the programme is their own work practices as owner-managers of SMEs. In other words, the learning they experience as a result of LEAD is situated back into their own contexts with the aspiration of developing entrepreneurial leadership. In this way, the negotiation of meaning is around the competence of being an entrepreneurial leader. In other words, a pedagogical context is created to increase the salience of leadership for owner-managers, thus enabling entrepreneurial leadership learning.

Using CoP theory as an analytical tool provides a pedagogical heuristic for entrepreneurial leadership learning, which helps the owner-managers to view themselves as leaders without explicitly 'teaching' them leadership. This pedagogy is based on constructionist views of knowledge which require the delegates to engage with the ideas that come from the different elements of LEAD and to develop skills and capabilities relevant to their own situations in their businesses. In CoP terms it enables them to address problems and share knowledge (Wenger, 2004). The circulation of knowledge within LEAD comes largely from the delegates and their experiences of running small businesses. This pedagogy includes learner-directed styles of learning and interactive approaches for the delegates to learn from each other and the knowledge they have about running small businesses. The learning is naturalistic through a continual process of participating in the CoP (and experiencing the learning interventions) and embedding their learning back in the own contexts, that is, their businesses. This loop and the trajectory back and forth between the CoP and the workplace is very important in the development of an entrepreneurial leadership identity, and it requires time for this to have an effect.

Conceptualising the programme as a CoP, Smith (2011) uses the term 'enablers' to show how the programme team and the facilitators create the environment for learning and for a CoP to emerge. The enablers are part of the construction of a situated curriculum which Gherardi et al. (1998: 275) have described as the 'pattern of activities that instruct the process socialization of novices in a context of ongoing work activities'. The enablers engage with the delegates in a form of a co-constructed situated curriculum. The delegates bring a language and meanings from their own businesses and blend these together through activities to form a unique $\mathrm{CoP}$. This is a co-construction between the delegates and the enablers which results in a CoP with a central focus on entrepreneurial leadership learning.

\section{HOW DOES A COMMUNITY OF PRACTICE IMPACT ON HUMAN, SOCIAL AND INSTITUTIONAL CAPITAL?}

We are beginning to understand how a CoP can be created in an entrepreneurial leadership development programme. In essence, we suggest, building a programme CoP enables a three-dimensional perspective to developing entrepreneurial leadership. Evaluation of the LEAD programme has shown that a significant impact occurs on the first two dimensions: first, the owner-managers' acquisition of human capital; and second, on the business through social capital (Wren and Jones, 2006). Additionally, in the third dimension, a programme CoP develops akin to Leitch et al.'s (2013) notion of institutional capital. While Leitch et al. (2013: 360) do not explore how this capital is developed, they acknowledge the need for social trust, which is itself developed from individuals having already learnt to cooperate. Our argument in this chapter is to assert that exploring how a programme CoP can be developed is central to explaining the interrelationship of social and institutional capital. $<$ a DEVELOPING HUMAN, SOCIAL AND INSTITUTIONAL CAPITAL

The penultimate section of this chapter illustrates the development of all three dimensions of human, social and institutional capital. We do this through a co-constructed autoethnographic approach that has been shown to enable the granular detail of leader becoming to be illuminated (Kempster and Stewart, 2010). Autoethnography 'does not merely require us to explore the interface between culture and self, it requires us to write about ourselves. It is the conscious experiencing of the self as both inquirer and respondent, as teacher and learner ... coming to know the self within the process of research' (ibid.: 210). The co-constructed aspect is a partnered process of a researcher pursuing an in-depth examination of a particular phenomenon experienced by the respondent. The outcome of co-constructed autoethnography is an aesthetic narrative that manifests as a 'theory sandwich' (Ellis, 2004: 198). The 'tasty' filling is the partner respondent; the 'ethno' cultured subject (Watson, 2011) with the 'graphy' as the spatial and temporal aspects of the experience. The 'dry' bread represents theory being developed through examining the partner respondent's lived experience. The next section outlines such an aesthetic narrative: a co-constructed autoethnographic examination of entrepreneurial leadership learning that draws on the preceding literature discussion of this chapter.

\section{Applying the Principles: The Case of Freddie Porter}

Barnes et al. (2015) provide a research based examination of entrepreneurial leadership learning in the small and medium-sized enterprise (SME) context through a real-life narrative encapsulating the development of three 
business people on a leadership programme, whilst explaining the key theories, models and techniques that underpin the leadership methods and approaches deployed. The learning journey of three SME business leaders was explored through a series of in-depth, semi-structured interviews aided by formal outputs of LEAD produced by the interviewees during and after the programme. Data were was collected through access to more than 150 pages of transcripts generated from interviews with three participants, and were was used in the narrative to describe their unfolding stories. Additionally, the meta-reflections of the three business leaders, captured in the 7000-word work-based learning submissions submitted as part of their Master's qualification, were accessed. The case of Freddie was selected to further explore the three different types of capital, as it was representative of entrepreneurial leadership learning in an established family business in a traditional industry, indicating that positive change is achievable.

Freddie Porter was one year into the Managing Director role of a century-old, medium-sized, familyowned, building materials company. He worked alongside his two brothers, his wife and his retired father who remained as Chairman. The company had laboured through the last ten years, led by an autocratic and highly directive board with poor leadership and ineffective communication. Communication was one way: top-down. Managers felt battered and bruised and the 80 employees were disengaged. Freddie's father had ruled with an iron glove, controlling all aspects of the business, and his sheer will and determination drove the organisation. Freddie not only had inherited the business but he had also unknowingly inherited some of his father's rather direct ways, though he was trying his best to adopt a more empowering style.

Freddie was concerned about the performance of his company as sales had ceased to grow. Old business methods and models had remained unchanged over past decades, with personnel and systems left to stagnate. The mentality embedded within the business was one of 'the company can run itself, we don't really need director intervention'. There was a severe lack of communication and planning.

Freddie was full of trepidation and scared of the responsibility of the role of Managing Director. Although it said 'Managing Director' on his business card, he did not feel like one. While he held the title he had the job responsibility, but he did not know how to do the role. It felt like the blind leading the blind. The management team were not up to standard and the family were all on top of each other, resulting in ill feeling. Freddie's enthusiasm and confidence were privately waning under his self-doubts.

The following are extracts from an interview with Freddie after he had completed the LEAD programme, in which he reflects on aspects of the programme. We have selected from his reflections extracts that resonate with entrepreneurial leadership learning focusing on human, social and institutional capitals.

\section{Human Capital: Leadership Learning}

'One of the first learning experiences was from my leadership timeline, which I populated with incidents and experiences from an early age. This was an invaluable exercise as I quickly discovered that the majority of my leadership experiences were based from negative memories. I now understand that I developed my own leadership from learning from the mistakes of other leaders that I have worked with in the past, thus creating my own style. This is why I believe that I sometimes come across too placid and not as authoritarian as I should be as a leader, as I have seen very aggressive styles of this leadership not working.

What also was quite startling to realise was how little support I had received from my family that were involved in the business. My father and directors had never taken me to one side to coach, nurture, praise, or reprimand when required.'

\section{Social Capital: Communications and Employee Engagement}

'[The] exercise involved four of us standing on a chess board with a manager directing us around the board via a radio linked through to directors. We were faced with pawn like pieces on the board and a competitor moving the pieces trying to win the game. At first my chess board colleagues and I were very jovial, appreciating the stress free nature of our job. However, when we seemed to be going nowhere and colleagues were getting taken out of the game, frustration started to occur. We questioned the manager's direction but she was only taking instruction from her director. We had worked out a way to win the game ourselves but the manager wasn't listening. We then started to argue amongst ourselves with two of my peers wanting to walk off and the other being a model employee. I was undecided on whether to depart or remain in the game with both sides trying to influence me. The manager could not control the situation. Morale and engagement were at a low.

This whole exercise provided me with a very steep learning curve and a realisation of my own business. I posed several questions to myself: How do the 'shop floor workers' feel in my organisation? Are we carrying out mushroom management? Do we ask them for their ideas? Do we communicate with them effectively or indeed at all? Are they bitter towards management due to a negative response to the questions posed above? The answer to this last question was yes which was a bolt out of the blue as I did not realise that was happening. 
I connected this learning with that from the Employee Engagement Masterclass to build a new communication structure within our business. An employee newsletter is now completed bi-monthly and sent to the employees' home (to curtail negativity amongst partners where the employee could make out an inaccurate image and description of the work place). Conducting a leadership questionnaire has helped to let the employees anonymously have their say on their manager's performance. The newly formed employee committee has allowed the 'voice' of the workforce to be heard and provided some very valid points, issues and ideas for the Company.

Directors have encouraged managers to relay essential information back to their teams after the key decision makers meeting, this wasn't happening before and information channels were blocked. These action plans have all been brought on by the realisation that communication wasn't working at all in our organisation. The Company endured a strict hierarchy with major barriers to cross-organisational communication with former long standing directors struggling to communicate between themselves meaning any interaction and exchange with staff at any level was minimal.'

\section{Both Human and Social Capitals: Leading In- and Out-Groups}

'From a leadership masterclass, I linked Leader Member Exchange [LMX] Theory with my organisation. We had very distinct sub groups. The financial controller and sales manager with access to a wide range of information were the 'in-group'. A sales office manager, interiors manager and operations manager were in the 'out-group'.

I have heavily relied on the information provided to me by the 'in-group' and made big decisions based on their knowledge and facts. Although I would listen to the 'out-group', they were on the periphery. This however has been to the detriment of the business and the two members of the 'in-group' no longer are at the company due to inaccurate information being provided.

I have learnt a harsh but very valuable lesson from this experience, and on reflection, I spent too much time relying and listening to the 'in-group' when the 'out-group' were holding key operational information which hadn't been tapped into. After my recent encounter with the LMX theory I realise being too close to an 'in-group' alienates the 'out-group' and does not promote employee relationships. For future reference, I will be extremely careful not to harbour strong links with certain managers who are on the same level as each other to avoid creating groups which would not be beneficial for relationships within the Company.'

\section{Institutional and Human Capitals: Personal Responsibility}

'I recognise that I cannot do it all and that I need a capable management team around me. Leaving managers to manage on their own is not suitable either. During the course of LEAD I have discussed replacing poor performing senior managers with my peers inside and outside of Action Learning Sets as well as with my coach. This is something that has never happened in our company's history, but because peers that I respect said it was the correct course of action, I have changed most of the senior team.

Due to LEAD, I have found myself constantly reflecting on every meeting that I have, which in turn, has aided me to evolve in my role as Managing Director. An example of this is a key decision makers meeting which I chair. I ensure that I am well prepared going into the meeting with a set agenda and forward this to members of staff to add content/points before the meet. As this is an important meeting, it is important that I listen intently and answer succinctly any questions posed. Prior to LEAD, I was a poor listener. I also asked closed questions rather than the open questions I have been coached to use in Action Learning.'

\section{Institutional, Social and Human Capitals: The Journey}

'My LEAD journey has provided me with the basis to form a new structure within the organisation. Before I started the programme I had certainly approached a cliff and realised I needed further learning, knowledge and peer support to help increase my skill level as a Managing Director in my company. I felt isolated in my environment and required an added impetus to help change my organisation. After obtaining new knowledge from some very beneficial Masterclasses, I was able to reflect on my learning from the Overnight Experiential and contextualised it opening my eyes to what was not working in my organisation. This helped me enormously in putting my new learning into practice to 'fix' what was being run poorly within the business.

Shadowing and Exchange helped increase my confidence further by 'living' in another business for two days, realising that my new knowledge and learning could also help another organisation.

The peer group that has been part of the LEAD programme have been a huge aid to my development . . having access to such a network is immeasurably important and I have learnt a wealth of information from just listening to other owner-managers. This has been the greatest support group I could have hoped for and I continue to network/socialise with my peers post-LEAD with continued personal and business gain for us all. 
I now feel that I have arrived at a major crossroads in my working career with implementation of key strategies being the future heartbeat of the organisation, with growth and expansion of the business not just a pipe dream but a reality. I have gained much experience, knowledge and learning over the past year and will be putting this further into practice over the coming years.'

\section{Reflections}

We hope the case study helps to demonstrate the interrelatedness of human, social and institutional capital. Leitch et al. (2013: 360) suggests such integration is needed for the development of entrepreneurial leadership within the small business relational context. We demonstrate the interrelatedness between each element below.

First, Freddie has developed his human capital; that is, improving his knowledge, skills and capabilities. This is evident through the acquisition of new knowledge he says he has gained from the learning interventions and the other owner-managers, which he has put into practice and plans to continue to do so. He has developed his practice to embrace open questions and active listening alongside, and increasing accent on reflection, for example reflecting back on events, during meetings, and reflecting forwards to prepare himself and his staff for when they meet. He highlights how his confidence has increased and identifies with aspiring to become a particular leader identity. A sense of a narrative identity (Ezzy, 1998) has emerged in that Freddie sees himself as central to developing his business, through establishing a business plan for the first time in the company's 100-year history, creating a new business unit and growing sales.

Second, Freddie has developed notions of internally oriented social capital (Adler and Kwon, 2014) with a particular orientation to relationships between individuals and organisations that facilitate action and create value (Hitt and Ireland, 2002). He recognised the need for a capable management team around him, resulting in a change of most of the senior team, in a sense implicitly taking the view that social capital development was limited by role incumbents. We see a mindfulness of Freddie toward his future behaviour and relationships with managers to seek to maximise social capital through being careful to create beneficial internal networks. More broadly, aspects of social cohesion and solidarity have been advanced with attention to communications. This is illustrated by the implementation of an employee engagement strategy. The consequence has been an overt change to Freddie's previous highly directive leadership practice. In a sense, giving a 'voice' to the workforce in turn has enabled issues and ideas to be circulated. Blockages have been addressed and communication has been encouraged between directors and managers to relay essential information back to their teams after the key decision-makers' meeting.

Third, institutional capital was developed through the creation of the LEAD CoP, that is, the formal structures and organisations which enhance the role of social capital and go beyond enriching the human capital stock of individual leaders (Anderson, 2010). This has been enabled through the expanded network of Freddie's LEAD peers, the business leaders who did not know each other previously coming together to create a CoP. Freddie's comments give clear recognition that this peer group has been a huge aid to his development. Leitch et al. (2013: 358) argue that the development of the reservoir of social capital (in our case, the LEAD peers) transcends the boundaries of each individual firm which provides the platform for the development of institutional capital. The structures and informal governance approaches, pedagogy and the rules of engagement within the LEAD CoP have enabled the creation of an institution. Comments from Freddie illustrate him drawing from the institutional capital in terms of its effect on his own entrepreneurial leadership development and his business. He recognises that his peers have been a most valuable support group. The ongoing presence of the institution is reflected in his continuing to network and socialise with them after the programme officially finished. The informal structures and governing rules of engagement have persisted. An example of this is where Freddie highlights how, through his engagement and investment in the CoP, he can see the benefit to himself, his own organisation, his peers and their organisation from 'his peers'. He cites how the process of 'shadowing' another business has added institutional value to the community as well as the participating businesses. The risks associated with the process are mitigated through the accepted governance of the relationships within the institution.

The case study brings together human, social and institutional capitals, showing how institutional capital can be developed through the establishment of a CoP (as in the above example of LEAD) that can enable the development of entrepreneurial leadership through nurturing and enhancing human, social and institutional capitals.

\section{NEXT STAGES FOR RESEARCH AND DEVELOPMENT IN ENTREPRENEURIAL LEADERSHIP LEARNING}

It has been our intention in this chapter to summarise what is known about entrepreneurial leadership learning. We have sought to elaborate the phenomenon in the context of emerging debates in the leadership field. In particular, we have highlighted how leadership is seen as a relational social process focusing on practices and identities vis-à-vis the essentialist qualities and characteristics of an individual; leadership as relational rather than individual. In terms of leadership learning the corollary is to look to social learning theory to give insight. 
In this chapter we have outlined social learning theory and its constituent, legitimate peripheral participation and communities of practice $(\mathrm{CoP})$ theory. Together, they provide a relational frame to understand notions of becoming in terms of practices and identities that are developed within particular situations through processes of legitimate peripheral participation. Knowing, being and doing become learned as a shared dynamic; a community of shared understanding. In the context of entrepreneurial leadership learning the relationship is between the owner-manager(s) and the employee(s). The practice of leading is the knowing, being and doing that emerges and is continually becoming and ongoing within this community of leadership practice. It is a form of learned occupational practice of leading.

The case of Freddie gives insight into the lived experience of entrepreneurial leadership learning as a collective and integrative process of human, social and institutional capital development. For us, this insight suggests a range of questions and avenues for researching entrepreneurial leadership learning. Our argument has proposed that this phenomenon is relational and that situated learning theory has much to offer in terms of what is occurring within entrepreneurial leadership learning. As such, our first research agenda is focused on learning. We suggest that this would need to be qualitative to understand the situated social learning processes. The focus on in-depth, thick descriptions (Orr, 1996) is needed to illuminate something of the emergent and opaque phenomenon that is situated learning. For example, how does an individual entrepreneur become an active member of a CoP? What stages of transition might be evident? How does the language and meaning become shared? Where is the language and meaning drawn from? How does this impact upon the individual and their businesses? How do the shared meanings and the shared repertoire of practices and identities within this CoP migrate across to the individual and their practice (human capital) within the entrepreneurial context (social capital)? How does a CoP emerge within a leadership development programme?

Our second research agenda is related to the first and is associated with the development of human, social and institutional capital. We have suggested that these three capitals are interrelated through the relational learning process of situated learning. In particular, notions of leader becoming (human capital) are informed by shared being, doing and knowing that occurs in the $\mathrm{CoP}$ - the programme cohort. Questions that follow this assertion are: What is the relationship of a $\mathrm{CoP}$ and the development of human capital, social and institutional capital? How do the three capitals operate inside a CoP? Can a CoP emerge without the presence of all three capitals?

The third research agenda is more specifically oriented to the three capitals. Leitch et al. (2013) have suggested that little is known of how these capitals interrelate, and comment that social capital and institutional capital reinforce each. However, we need to know how. Further, we need to understand the tripartite relationship of all three. How does social and human capital development, as emergent and ongoing in the entrepreneurial context, shape the institutional capital? What happens when the LEAD CoP ends? We are assuming that all three capitals malleably interact, but is this so? Are there significant time lags between these? Does one capital have greater influence than the others? Final big questions: how valuable are the three capitals to business survival and growth?

These three connected research agendas would point towards important policy issues related to the efficacy and effectiveness of leadership development designs for the development of entrepreneurial leadership and for the development of the small business.

To address these three research agendas and the policy aspect of business survival and growth, we suggest a comprehensive research programme that is centred on a longitudinal design: a study which tracks LEAD participants and their businesses over time (see Barnes et al., 2015, for an illustration of such longitudinal research). Although we have suggested above the need for qualitative research to address the range of research questions we have outlined, this should not mean that quantitative research should be ignored. Rather, we suggest that a mixed-methods approach (Bryman, 2006) would usefully allow detailed examination of the interrelated issues. The range and number of businesses that have undertaken the LEAD programme provide a data set that would enable complementary quantitative and qualitative examination. For example, more than 2000 owner-managers have engaged on the LEAD programme. Although this has been helpfully evaluated, it has not sought to attend to an understanding the development of entrepreneurial leadership learning and the related aspects of situated learning, CoP and the three capitals. First, this data set could be base-lined through qualitative and quantitative approaches to understand, for example, whether the manifestation of the three capitals has occurred, whether they have been sustained, and what impact is evident. This may reflect questionnaires and interviews, but also other possible approaches such as repertory grid, critical incidents and narrative analysis. Subsequently, LEAD cohorts could be followed to address the research agenda. Respondents might include the owner-managers, of course, but also colleagues in their organisations (to explore internal social capital), possibly other business stakeholders (customers, suppliers), as well as leadership development practitioners. Approaches additional to interview might include ethnography, autoethnographies, critical incidents and possibly questionnaires. By undertaking a complementary mixed-methods approach this would allow for a robust elaboration of the development of entrepreneurial leadership learning through a relational lens and its relationship with and between the three capitals. 


\section{CONCLUSION}

Although the phenomenon of entrepreneurial leadership learning is at the very early stages of construction and understanding, our chapter has provided an illumination of the salient aspects that can help further research and development to occur. In this way we hope we have been able to build upon Leitch et al.'s (2013: 361) call for more research and theory development for the integration of institutional capital with social and human capitals. We hope the exploration we have outlined, of a social learning dynamic of entrepreneurial leadership learning incorporating the three capitals, has embraced such integration and provides a platform for future theorybuilding and complementary empirical research. The need for understanding the development of entrepreneurial leadership interconnected with the three capitals is most important for the growth of businesses and the societies in which they are embedded; in a sense, generating a fourth capital: economic capital.

\section{REFERENCES}

Adler, P.S. and Kwon, S-W. (2014) Social capital: Prospects for a new concept. Academy of Management Review, 27(1): 17-40.

Alvesson, M. and Sveningsson, S. (2003) The great disappearing act: Difficulties in doing 'leadership'. Leadership Quarterly, 14(3): 359381.

Anderson, L.E. (2010) Social Capital in Developing Democracies: Nicaragua and Argentina Compared. Cambridge: Cambridge University Press.

Avolio, B.J. (2005) Leadership Development in Balance: Made/Born. Hillsdale, NJ: Erlbaum.

Bagheri, A. and Pihie, Z.A.L. (2011) Entrepreneurial leadership: Towards a model for learning and development. Human Resource Development International, 14(4): 447-463.

Barnes, S., Kempster, S. and Smith, S. (2015) LEADing Small Business: Business Growth through Leadership Development. Cheltenham, UK and Northampton, MA, USA: Edward Elgar Publishing.

Bennis, W.G. and Thomas, R.G. (2002) Crucibles of leadership. Harvard Business Review, 80(9): 39-46.

Brown, J.S. and Duguid, P. (1991) Organizational learning and communities of practice: toward a unified view of working, learning and innovation. Organization Science, 2: 40-57.

Bryman, A. (2006). Integrating quantitative and qualitative research: How is it done?. Qualitative Research, 6: $97-113$.

Carroll, B., Levy, L. and Richmond, D. (2008) Leadership as practice: Challenging the competency paradigm. Leadership, 4(4): 363-379.

Cogliser, C.C. and Brigham, K.H. (2004) The intersection of leadership and entrepreneurship: Mutual lessons to be learned. Leadership Quarterly, 15: 771-799.

Cooney, T.M. (2005) Editorial: What is an entrepreneurial team?. International Small Business Journal, 23(3): 226-235.

Cope, J. (2005) Toward a dynamic learning perspective of entrepreneurship. Entrepreneurship Theory and Practice, 29(4): 373-397.

Cope, J., Kempster, S. and Parry, K. (2011) Exploring distributed leadership in the small business context. International Journal of Management Reviews, 13(3): 270-285.

Cope, J. and Watts, G. (2000) Learning by doing: An exploration of experience, critical incidents and reflection in entrepreneurial learning. International Journal of Entrepreneurship Behaviour and Research, 6(3): 104-124.

Cox, C.J. and Cooper, C.L. (1989) The making of the British CEO: childhood, work experience, personality, and management style. Academy of Management Executive, 3(3): 241-245.

Davies, J. and Easterby-Smith, M. (1984) Learning and developing from managerial work experience. Journal of Management Studies, 21(2): 169-183

DeRue, D.S. and Ashford, S.J. (2010) Who will lead and who will follow? A social process of leadership identity construction in organizations. Academy of Management Review, 35: 627-647.

Drath, W.H., McCauley, C.D., Palus, C.J., Van Velsor, E., O’Connor, P.M.G. and McGuire, J.B. (2008) Direction, alignment, commitment: Toward a more integrative ontology of leadership. Leadership Quarterly, 19(6): 635-653.

Ellis, C. (2004) The Ethnographic I: A Methodological Novel about Autoethnography. Walnut Creek, CA: AltaMira Press.

Ezzy, D. (1998) Theorizing narrative identity: Symbolic interactionism and hermeneutics. Sociological Quarterly, 39(2): 239-252.

Fernadez, R.M. and Castilla, E.J. (2001) How much is that network worth? Social capital in employee referral networks. In K. Cook, N. Lin and R.S. Burt (eds), Social Capital: Theory and Research. Chicago, IL: Aldine-de-Gruyter, pp. 85-103.

Gartner, W.B., Shaver, K.G., Gatewood, E. and Katz, J.A. (1994) Finding the entrepreneur in entrepreneurship. Entrepreneurship Theory and Practice, 18(3): 5-9.

Gherardi, S. (1995) Organizational learning. In Warner, H. (ed.), International Encyclopaedia of Business and Management (pp. 39343942). London: Routledge \& Kegan Paul.

Gherardi, S., Nicolini, D. and Odella, F. (1998) Towards a social understanding of how people learn in organizations: The notion of a situated curriculum. Management Learning, 29(3): 273-297.

Grint, K. (2010) The sacred in leadership: Separation, sacrifice and silence. Organizations Studies, 31(1), 89-107.

Gupta, V., MacMillan, I.C. and Surie, G. (2004) Entrepreneurial leadership: Developing and measuring a cross-cultural construct. Journal of Business Venturing, 19: 241-260.

Hill, L.A. (2003) Becoming a Manager: How New Managers Master the Challenges of Leadership. Harvard, MA: Business School Press

Hitt, M.A. and Ireland, R.D. (2002) The essence of strategic leadership: Managing human and social capital. Journal of Leadership and Organization Studies, 9(1): 3-14.

Iles, P. and D. Preece (2006) Developing leaders or developing leadership? The Academy of Chief Executives' programme in the North East of England. Leadership, 2: 317-340.

Jackson, B. and Parry, K. (2001) The Hero Manager: Learning from New Zealand's Top Chief Executives. Auckland: Penguin Books.

Janson, A. (2008) Extracting leadership knowledge from formative experiences, Leadership, 4(1): 73-94.

Jensen, S.M. and Luthans, F. (2005) Entrepreneurs as authentic leaders: Impact on employees' attitudes. Leadership and Organization Development Journal, 27(8): 646-666.

Kelly, S. (2014) A negative ontology of leadership. Human Relations, 67(8): 905-922

Kempster, S.J. (2006) Leadership learning through lived experience: a process of apprenticeship? Journal of Management and Organization, 12(1): 4-22.

Kempster, S.J. (2009) How Managers Have Learnt to Lead: Exploring the Development of Leadership Practice. Basingstoke: Palgrave Macmillan.

Kempster, S. and Cope J. (2010) Learning to lead in the entrepreneurial context. International Journal of Entrepreneurial Behaviour and Research, 16(1): 5-34. 
Kempster, S. and Stewart, J. (2010) Becoming a leader: A co-produced autoethnographic exploration of situated learning of leadership practice, Management Learning, 41(5): 205-219.

Lave, J. and Wenger, E. (1991) Situated Learning: Legitimate Peripheral Participation. Cambridge: Cambridge University Press

Leitch, C.M., McMullan, C. and Harrison, R.T. (2013) The development of entrepreneurial leadership: The role of human, social and institutional capital. British Journal of Management, 24: 347-366.

McCall, M.W. (2004) Leadership development through experience, Academy of Management Executive, 18(3): 127-130.

McCall, M.W., Lombardo, M.M. and Morrison, A.M. (1988) The Lessons of Experience: How Successful Executives Develop on the Job. Lexington, MA: Lexington Books.

Meindl, J. (1995) The romance of leadership as a follower-centric theory: A social constructionist approach. Leadership Quarterly, 6(3): 329-341.

Nahapiet, J. and Ghoshal, S. (1998) Social capital, intellectual capital, and organizational advantage. Academy of Management Review, 23: 242-266.

Orr, J.E. (1996) Talking about Machines: An Ethnography of a Modern Job. Ithaca, NY: Cornell University Press.

Pittaway, L. and Thorpe, R. (2012) A theory of entrepreneurial learning: A tribute to Jason Cope. Entrepreneurship and Regional Development, 24(9/10): 837-859.

Raelin, J. (2011) From leadership-as-practice to leaderful practice. Leadership, 7(2): 195-211.

Renko, M., Tarabishy, A.E., Carsud, A.L. and Brannback, M. (2015) Understanding and measuring entrepreneurial leadership style. Journal of Small Business Management, 53(1): 54-74.

Ruvio, A, Rosenblatt, Z. and Hertz-Lazarowitz, R. (2010) Entrepreneurial leadership vision in non-profit vs. for profit organizations. Leadership Quarterly, 21: 144-158.

Smith, S. (2011) How do small business owner-managers learn leadership through networked learning? In Dirckinck-Holmfeld, L., Hodgson, V. and McConnell, D. (eds), Exploring the Theory, Pedagogy and Practice of Networked Learning. New York: Springer, pp. 221-236.

Smith, S and Smith, L. (2013) 'I am therefore I think': Exploring the complexities of identity within action learning for entrepreneurs. Paper presented at the British Academy of Management Conference, September, Liverpool.

Surie, G. and Ashley, A. (2008) Integrating pragmatism and ethics in entrepreneurial leadership for sustainable value creation. Journal of Business Ethics, 81(1): 235-246.

Taylor, D.W. and Thorpe, R. (2004). Entrepreneurial learning: A process of co-participation. Journal of Small Business and Enterprise Development, 11: 203-211.

Thorpe, R., Cope, J., Ram, M. and Pedler, M. (2009). Leadership development in small- and medium-sized enterprises: The case for action learning. Action Learning: Research and Practice, 6(3): 201-208.

Uhl-Bien, M. (2006) Relational leadership theory: Exploring the social processes of leadership and organizing. Leadership Quarterly, 17: 654-676.

Vecchio, R.P. (2003) Entrepreneurship and leadership: Common trends and common threads. Human Resource Management Review, 13: 303-327.

Watson, T.J. (2011) Ethnography, reality, and truth: The vital need for studies of 'how things work' in organizations and management. Journal of Management Studies, 48: 202-217.

Wenger, E. (1998) Communities of Practice: Learning, Meaning, and Identity. Cambridge: Cambridge University Press.

Wenger, E. (2000) Communities of practice: The key of knowledge strategy. In Lesser, E.L., Fontaine, M.A. and Slusher, J.A. (eds), Knowledge and Communities. Woburn, MA: Butterworth-Heinemann, pp. 3-20.

Wenger, E. (2004) Learning for a small planet: A research agenda. Paper presented at the annual meeting of the American Educational Research Association, San Diego, CA, April.

Wren, C. and Jones, J. (2006) Ex-post evaluation of the LEAD Programme. Unpublished report, University of Newcastle Upon Tyne. Available at http://www.lums.ac.uk/leaddeval.

Wren, C. and Jones, J. (2012) Quantitative evaluation of the LEAD Programme, 2004-11. University of Newcastle Upon Tyne. Available at http://www.ncl.ac.uk/nubs/research/publication/192709.

Zhu, W., Chew, I.K.H. and Spangler, W.D. (2005) CEO transformational leadership and organizational outcomes: The mediating role of human-capital-enhancing human resource management. Leadership Quarterly, 16: 39-52. 